\title{
QUANTUM FIELD OF FUNCTIONAL DENSITY
}

Eugene Machusky, Olexander Goncharov

Kyiv Polytechnic Institute, Ukraine

\begin{abstract}
For the first time in scientific and engineering practice, it is logically and mathematically substantiated, computationally verified and metrologically confirmed that classic and quantum physics, analytical and quantum chemistry, as well as continuous symbolic and discrete digital mathematical analysis, all have computational limits of information entropy, upper $1 / 10^{\wedge} 16$ and lower $1 / 10^{\wedge} 64$. Mutual displacement of these limits relatively center of Euclidean three-dimensional and of Cartesian two-dimensional space generate sets of quantum dots of mesh topology and weighted average harmonic units of quantum metrics of internal atomic and outer cosmic space, as well as determines limits of communication speed, clock frequency, calculation power and accuracy for any computing machine with subatomic elements of memory. The matrices of functional density and entropy of energy and information fields reconciles classic and quantum physics with continuous and discrete mathematics of special and general relativity.

\section{INTRODUCTION}

All natural sciences are based on practical observations, measurements and subsequent description of the parameters of motion of material bodies, particles and waves in the inner subatomic and in outer cosmic space. Today, three theories - "functional density", "three body waves", "energy diagrams", developed by W. Kohn, J. Schwinger and R. Feynman half a century ago, are the most successful in physics, materials science, chemistry and cosmology. But only the theory of functional density shows that the total energy of an atomic system described by quantum mechanics could be exactly calculated if the spatial distribution of all electrons were known, and to describe the motion of an individual electron it is sufficient to determine the average density of electrons at each point of the system.

The phenomenal efficiency of quantum physics in modern information and communication systems has a simple explanation from the point of view of common sense and mathematical logic: quantum physics, quantum chemistry, quantum metrics and quantum calculus are all genetically interconnected natural self-information systems based on functional analysis and calculations of the motion of matter in various states and conditions of the material environment.

To confirm this, it is enough to determine the possible trajectories of movement of a pulsating elastic ball of diameter "e" inside a sphere of diameter "pi" in geometric, trigonometric, algebraic, logarithmic and arithmetic forms. This was done by hyperbolic contraction of the inverse natural set $[1 \ldots 1 /(\mathrm{N}+1)]$ with transfer to the inverse exponential space $\left[1 / \mathrm{e}^{\wedge} \mathrm{N} \ldots 1 / \mathrm{pi}^{\wedge} \mathrm{N}\right]$. Such an algorithm creates an analytical system for fast integro-differential calculation of the parameters of motion of material bodies and waves both in the infinitely small subnuclear and in the infinitely large outer interstellar space, [1]-[14].

\section{FUNCTIONAL DENSITY OF QUANTUM SPACE}

Functionals are functions of functions. A functional, like a function, is a relationship between objects, but the objects may be numbers, vectors, or functions. Differentiation and integration are functionals. 
It was discovered that to calculate the fundamental quantum constants of the standard physical model with extremal accuracy $1 / 10^{\wedge} 64$, there are enough only two expressions: the absolute speed functional $C=\left(R / 10^{\wedge} 8+4 * \mathrm{pi}^{*} \mathrm{C} / 10^{\wedge} 18\right)^{\wedge} 64^{*} 10^{\wedge} 7$ by Maxwell, as $\mathrm{R}=$ Integer $\left\{10^{\wedge} 8^{*}\left(\mathrm{C} / 10^{\wedge} 7\right)^{\wedge}(1 / 64)\right\}=105456978$, plus temperature functional $K=\mathrm{e}+\mathrm{AS}+\mathrm{BS}$ by Kelvin, $\mathrm{AS}=729 / 10^{\wedge} 5=10^{\wedge} 0 / 10^{\wedge} 2 /\left[10^{\wedge} 1 /\left(10^{\wedge} 1-10^{\wedge} 0\right)\right]^{\wedge} 3$ and $B S=602817 / 10^{\wedge} 8=\operatorname{Lim}\left\{\operatorname{Sum}\left[602214183 / 10^{\wedge}\left(3^{*} N+8\right)\right]\right\}$, but if and only if the length of the mantissa of the numbers "pi" and "e" in the decimal positional system is not less 64 bits.

$$
\begin{aligned}
& C=[299792457.86759133843368398914990500927337258665405914040533114633] \\
& K=[2.7315999984590452353602874713526624977572470936999595749669676277] .
\end{aligned}
$$

The approximate metric unit of temperature $K=2.7316=27316 / 10^{\wedge} 4$ was obtained as a result of thermodynamical description of the steam engines and was associated with the "triple point of water" (ice, water, vapor or crystal, liquid, gas) TPW $=K^{*} 100-1 / 100=273.15$ degrees Celsius. At the same time the unit of normalized pressure in millimeters (1/1000) of "water column" was introduced. Thus, the decimal normalizations $\left(1 / 10^{\wedge} 2,1 / 10^{\wedge} 3\right.$ and $\left.1 / 10^{\wedge} 4\right)$ of temperature and pressure were implemented into international system of metrology from the very beginning.

The metric unit of the speed of light "c" was originally introduced in electrodynamics as a value very close to $3^{*} 10^{\wedge} 8 \mathrm{~m} / \mathrm{s}$, and later, as a result of precise measurements by various methods, it was defined as $299792458=2.99792458 * 10^{\wedge} 8$ (decimal normalization) and with the specified error in the last digit. In modern metrology, this nine-digit number is used with the voluntary consent of the majority of the scientific community as an absolutely "exact" value of the translational velocity of massless material particles - photons. The concept of "massless material particle" is nonsense from the point of view of common sense and physical logic - any part of a material object has a mass, even if it is infinitely small. But from the point of view of elementary mathematical logic, any particle of a material object is its fraction - a relative, and therefore dimensionless, numerical value.

A paradox immediately arises here: if all photons have zero mass and all move at the same speed, but we want to describe the energy of one photon, the total number of photons should be infinite, but the sum of their masses should be zero. Mathematically, this can be expressed using the Lorentz functional Sqrt $\left(1-1 / N^{\wedge} 2\right)=1$, when $N$ tends to infinity, and this was implicitly introduced in special relativity as $[h * f]=\left[m^{*} c^{\wedge} 2\right]$. But if we additionally implement the complex conjugate functional Sqrt $\left(1+1 / N^{\wedge} 2\right)=1$ as $\mathrm{N}$ tends to infinity, the logical paradox becomes clear. Common sense, physical and mathematical logic of elementary counting says that $h^{*} f *\left[1+(v / c)^{\wedge} 2\right]=m^{*} v^{\wedge} 2 / 2 *\left[1+(v / c)^{\wedge} 2\right]$ and $[h * f]$ can be equal to $\left[\mathrm{m}^{*} \mathrm{c}^{\wedge} 2\right]$ if and only if $[\mathrm{v}=\mathrm{c}]$. In classical electrodynamics, this is well known as the "normal" and "anomalous" dispersion of forward and backward traveling electromagnetic waves.

Thus, the definition of the unified speed and zero mass of photons already contains an obvious logical error: the category "distance" (metric unit "meter") is directly related to the category "duration" (metric unit "second"), as in the paradoxical phrase "dig a trench from the fence to lunch". The physical logic of common sense and the mathematical logic of counting allow directly connecting only homogeneous or dimensionless quantities, such as gradients, derivatives and differentials - acceleration, temperature, frequency, wavelength, but not a direct ratio of space and time units. 
Quantum mechanics brilliantly eliminates logical delusions, synonymously introducing different, but geometrically interrelated parameters of particle motion: vibrational speed (the rate of movement along the radius of a sphere - the term "Temperature"), rotational speed (the rate of movement along the perimeter of a circle - the term "Celerity"), translational speed (weighted average rate - the term "Velocity"). Quantum electrodynamics avoids paradoxes by introducing two additional terms - "group" and "phase" velocity of traveling waves.

As a result, we got five different, but deeply mathematically and logically related concepts of speed and five corresponding sections of physics: mechanics, thermodynamics, electrodynamics, chromodynamics, gravidynamics, which together completely describe the transfer of thermal, electrical and gravitational energy in any direction from any starting point in pulsating three-dimensional Euclidean space.

\section{CONCLUSION}

Inductive-deductive (binary) mathematical logic (counting only the entropy and energy) does not work successfully both in symbolic classical and discrete quantum physics, so abductive (triple and fuzzy) logic of counting energy, entropy and information must be implemented. As a result of the development of such fuzzy logic algorithms, a finite set of web matrices for integrodifferential quantum metrics has been derived analytically and without any measurements. Spider webs of vector-tensor functionals, which establish both static and dynamic relations of nonperiodic and finite (rational), of periodic and infinite (irrational), and nonperiodic and infinite (transcendental) naturally normalized recursive digital waves, harmonizes discrete numerical and continuous symbolic analysis with a special and general relativity.

\section{REFERENCES}

1. Мачуський Є. «Електрон»/ ISBN 978-966-622-572-9/ Київ, НТУУ «КПІ», 2013.

2. Machusky E.A. "Logarithmetic of Quantum Physics"/ $16^{\text {th }}$ Int. Sc. M.Kravchuk Conf., vol.2 "Algebra. Geometry. Analysis"/ Kyiv, NTUU “KPI”, May 14-15, (2015).

3. Мачуський $Є . A$ «Диференціальна альфа-система числення в обернених кільцях»/ V Міжнар. наук.-практ. конф. «Методи та засоби кодування, захисту й ущільнення інформації»/ Вінниця, 19-21 квітня, (2016).

4. Eugene Machusky "Demystification of Quantum Physics"/ script and film by Lyubov Lisovska www.youtube.com/ August 26, (2016).

5. Eugene Machusky “Analytics of Quantum Physics or Quantum Language of Universe"/ Workshop Quantum-2017/ Torino, Italy, May 7-13, (2017).

6. Eugene Machusky "Quantum Metric of Classic Physics"/ IOP conf. series: Material Science and Engineering/ Online ISSN: 1757-899X, vol. 239, (2017).

7. Eugene Machusky "Quantum Physics as Dynamic Space-Time Differential Calculus"/ $3^{\text {rd }}$ Int. Conf. on Theoretical and Condensed Matter Physics/ New York, USA, October 19-21, (2017).

8. Eugene Machusky "Complex Geometry of Wave Motion"/ Int. J. of Engineering and Technology, v.10, no.2, (2018).

9. Eugene Machusky "Natural Qubit Matrix of Primary Elements of Matter"/ MATEC web of Conferences, 186, 01005, (2018). 
10. Eugene Machusky "Quantum Alphabet of Matter Language"/ Int. Conf. on Material Science and Engineering/ Rome, Italy, June 25-26, (2018).

11. Eugene Machusky "Transfinite Wave Mathematics of Relative Space-Time"/ VII Міжн. наук.-пр. конф. «Обробка сигналів і негаусівських процесів»/ Черкаси, Україна, 23-24 травня (2019).

12. Eugene Machusky "Quantum Information Paradigm of Physical Reality"/ Global Cyber Security Forum 2019/ Харків, Україна, 14-16 листопада, (2019).

13. "A Quantum Melody and Painting of Dancing Electron"/ E.Machusky, O.Goncharov, Sof. Mikadse, Sal. Mikadse/ Research J. of Nanoscience and Engineering, ISSN 2637-5591, v.4, iss.1, (2020)

14. Eugene Machusky “Quantum Web of Gravity”/ www.preprints.org/ November 23, (2020).

15. "Quantum Determinism of Relative Spacetime Counting"/ Machusky E., Lisovska L. Goncharov O./ www.preprints.org/ November 27, (2020). 
pi $=2 * \operatorname{Sum}\left\{1 / \mathrm{N} / \operatorname{Sqrt}\left(1-1 / \mathrm{N}^{\wedge} 2\right)\right\}=3.1415926535897932 \ldots$

$e=(1+1 / N)^{\wedge} N=2.7182818284590452 \ldots$

$A=137$.

$B=602214183$.

$C=\left(R / 10^{\wedge} 8+4 * \mathrm{pi}^{*} \mathrm{C} / 10^{\wedge} 18\right)^{\wedge} 64^{*} 10^{\wedge} 7=299792457.867591338 \ldots$

$R=$ Integer $\left\{10^{\wedge} 8^{*}\left(C / 10^{\wedge} 7\right)^{\wedge}(1 / 64)\right\}=105456978$.

$\mathrm{K}=(\mathrm{e}+\mathrm{AS}+\mathrm{BS})=2.731599994590452 \ldots$

AS $=1 / 100 / \operatorname{Sum}\left\{\left[A+(A-100)^{*} N\right] /\left(10^{\wedge}(3 * N+2)\right\}=0.00729\right.$.

$B S=\operatorname{Sum}\left\{B /\left(10^{\wedge}\left(3^{*} N+8\right)\right\}=0.00602817\right.$.

$X=R 00$

\section{FUNCTIONAL OF COSMOLOGICAL TIMING}

If any four, three, two, or one letter A, B, C, D are any digits of decimal alphabet $[0,1,2,3,4,5,6,7,8,9]$ than their positional location in any combination from 0001 to 9999 always will give the same result:

$$
\{[\mathrm{ABCD}] *[10000]+[\mathrm{ABCD}]\} /[\mathrm{ABCD}] /[\mathrm{73}] /[137]=1
$$

\section{FUNCTIONAL OF ABSOLUTE SPEED}

The absolute value of speed can be obtained from the following equation after several iterations:

$C=\left(R 0 / 10^{\wedge} 8+4 * \mathrm{pi}^{*} \mathrm{C} / 10^{\wedge} 18\right)^{\wedge} 64^{*} 10^{\wedge} 7$,

where R0 $=$ Integer $\left\{10^{\wedge} 8^{*}\left(c / 10^{\wedge} 7\right)^{\wedge}\left(1 / 10^{\wedge} 64\right)\right\}=105456978$ and where $c=299792458$ is metric value of speed and $4{ }^{*} \mathrm{pi}^{*} \mathrm{C} / 10^{\wedge} 7$ is Maxwell's wave impedance in free space. Unexpectedly, it turned out that as an initial approximation, we can take not only "c", but also any natural number from 0 to $10^{\wedge} \mathrm{N}$, and the result of the calculation will always be the same:

$C=[299792457.86759133843368398914990500927337258665405914040533114633]$.

$\mathrm{CO}=[299792458]=\mathrm{c}$.

[299792457.8675913687064157576343]

[299792457.867591338433690910436457457455603930109083]

[299792457.867591338433683989151487430308496050480564633752287172595]

[299792457.867591338433683989149905009635163174780407622241383002658]

[299792457.86759133843368398914990500927337266937062240107800267317]

[299792457.867591338433683989149905009273372586654078051980320121511]

[299792457.867591338433683989149905009273372586654059140409654920365]

[299792457.86759133843368398914990500927337258665405914040533114815] 
[299792457.86759133843368398914990500927337258665405914040533114633] [299792457.86759133843368398914990500927337258665405914040533114633]

$\mathrm{CO}=[0]$.

[299792389.3257336184180985487436]

[299792]457.8675756676365539058006765362779693963187184]

[299792]457.867591338430101158294993377726574617214373226141849240158] [299792457.86759133843368398833075861688825609553208760965328843345] [299792457.867591338433683989149904821991070035951849130170005033833] [299792457.867591338433683989149905009273329768103950452836644531478] [299792457.867591338433683989149905009273372586644269490190443217013] [299792457.867591338433683989149905009273372586654059138167113105362] [299792457.867591338433683989149905009273372586654059140405330635082] [299792457.86759133843368398914990500927337258665405914040533114633] [299792457.86759133843368398914990500927337258665405914040533114633]

$\mathrm{CO}=[999999999 \ldots]$

[299792617.9568211172233846309607]

[299792457.8676279398029206202859051075044254241673052]

[299792457.867591338442052198753057337244246247299108588009371562328] [299792457.867591338433683991063137585616635714678069826378474208344] [299792457.867591338433683989149905446697751847204018068673697447147] [299792457.867591338433683989149905009273472595450656772724070848693] [299792457.867591338433683989149905009273372586676924256917159327787] [299792457.867591338433683989149905009273372586654059145633006819219] [299792457.867591338433683989149905009273372586654059140405332341668] [299792457.86759133843368398914990500927337258665405914040533114633] [299792457.86759133843368398914990500927337258665405914040533114633]

FUNCTIONAL OF ABSOLUTE TEMPERATURE

FUNCTIONAL GEOMETRY AND QUANTUM TOPOLOGY OF SUBATOMIC SPACE 